\title{
Groin abnormalities: ultrasonographic and clinical findings
}

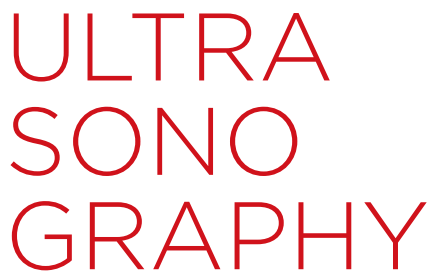

\author{
Dal Mo Yang ${ }^{1}$, Hyun Cheol Kim', Sang Won Kim', Kyu Yeoun Won ${ }^{2}$ \\ Departments of ${ }^{1}$ Radiology and ${ }^{2}$ Pathology, Kyung Hee University Hospital at Gangdong, \\ Seoul, Korea
}

Groin lesions can be classified as neoplastic or non-neoplastic. Neoplastic lesions include lipoma, epidermoid cyst, angiomyofibroblastoma-like tumor, liposarcoma, and synovial sarcoma, as well as metastases from lymphoma, neuroendocrine carcinoma, and carcinomas of the lung, breast, urinary bladder, ovary, vulva, and colon. Non-neoplastic lesions include hernias, round ligament varices, endometriosis, Kimura disease, Castleman disease, hematoma, and inflammation. Because the clinical implications and therapeutic strategies for groin lesions vary depending on the cause, the ability to noninvasively differentiate among etiologies is very important. Although there is substantial overlap in ultrasonographic findings across various groin lesions, some ultrasonographic features, along with clinical characteristics, may suggest a specific diagnosis. Familiarity with the ultrasonographic and clinical features of various groin lesions facilitates accurate diagnosis and treatment.

Keywords: Groin; Ultrasonography; Ultrasonography, Doppler, color

\section{Introduction}

There are many diverse abnormalities of the groin, and the differential diagnosis of groin lesions can be puzzling for many clinicians because of their similar clinical presentations [1,2].

Ultrasonography is considered to be the first-line imaging modality for groin lesions. Ultrasonography is accurate for distinguishing between solid and cystic lesions and may play an important role in distinguishing between benign and malignant lesions.

In this article, we review the relevant literature and discuss the ultrasonographic and clinical features of groin lesions (Table 1). Groin lesions can be classified as either neoplastic or nonneoplastic. Neoplastic lesions include lipoma, epidermoid cyst, angiomyofibroblastoma-like tumor, liposarcoma, synovial sarcoma, and lymphoma, as well as metastases from neuroendocrine carcinoma and carcinomas of the lung, breast, urinary bladder, ovary, vulva, and colon. Non-neoplastic lesions include hernias, round ligament varices, endometriosis, Kimura disease, Castleman disease, hematoma, and inflammation.

\section{Non-neoplastic Lesions}

\section{Hernia}

Inguinal hernias are classified as direct or indirect depending on their relationship to the inferior

\section{PICTORIAL ESSAY}

https://doi.org/10.14366/usg. 19041 pISSN: 2288-5919 • elSSN: 2288-5943 Ultrasonography 2020;39:166-177

Received: July 8, 2019

Revised: August 2, 2019

Accepted: August 5, 2019

Correspondence to: Dal Mo Yang, MD, Department of Radiology, Kyung Hee University Hospital at Gangdong, 892 Dongnamro, Gangdong-gu, Seoul 05278, Korea

Tel. +82-2-440-6183

Fax. $+82-2-440-6932$

E-mail:dmy2988@daum.net

This is an Open Access article distributed under the terms of the Creative Commons Attribution NonCommercial License (http://creativecommons.org/ licenses/by-nc/4.0/) which permits unrestricted noncommercial use, distribution, and reproduction in any medium, provided the original work is properly cited.

Copyright (c) 2020 Korean Society of Ultrasound in Medicine (KSUM)

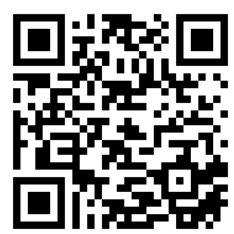

How to cite this article:

Yang DM, Kim HC, Kim SW, Won KY. Groin abnormalities: ultrasonographic and clinical findings. Ultrasonography. 2020 Apr;39(2):166-177. 
epigastric artery. Indirect inguinal hernias originate at the deep inguinal ring, lateral to the inferior epigastric vessels, and follow the course of the inguinal canal. Direct inguinal hernias pass through a defect of the Hasselbach triangle, which is medial to the inferior epigastric artery. Hernia contents include bowel loops, omental fat, and ovarian and peritoneal fluid [1,2]. On ultrasonography, hernia contents can be hyperechoic due to omental fat (Fig. 1), anechoic due to fluid, or have mixed echogenicity due to reverberations of air in the bowel loops $[1,2]$.

Pseudomyxoma peritonei occurs as result of a ruptured appendiceal mucocele or intraperitoneal spread of mucinous tumors,

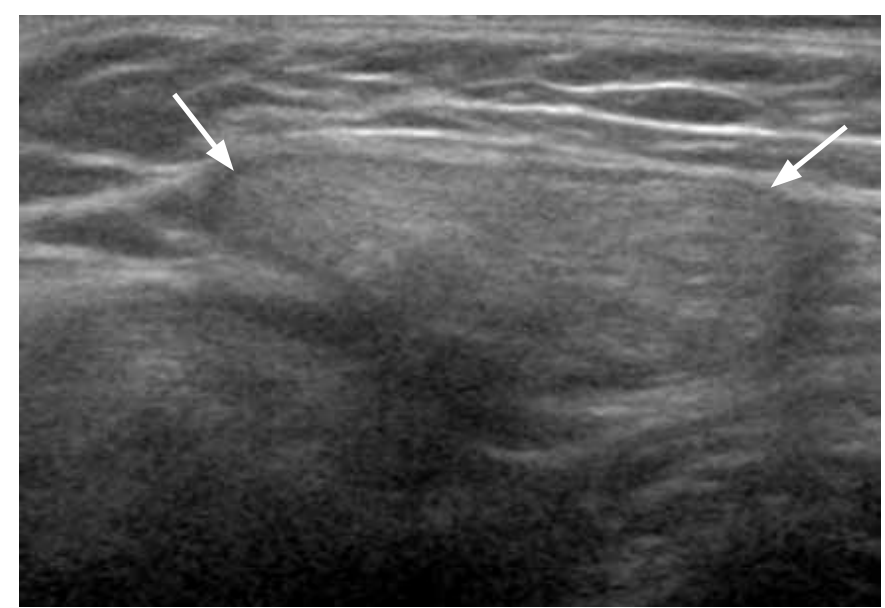

Fig. 1. A 3-year-old girl with a left inguinal hernia containing omental fat. Transverse ultrasonography shows an ovoid-shaped hyperechoic lesion in the left inguinal region (arrows). including mucinous adenocarcinomas of the ovary, appendix, and colon [3]. In patients with pseudomyxoma peritonei, the tumor may metastasize transcoelomically to implant within the peritoneal lining of the hernia sac [3]. If the hernia contents are echogenic with septated ascites and an irregularly thickened peritoneum on ultrasonography, there is a high possibility of pseudomyxoma peritonei (Fig. 2) [3].

\section{Spermatic Cord Hydrocele}

Spermatic cord hydrocele is a loculated fluid collection along the spermatic cord that results from failure of closure of the processus vaginalis [4]. Two types of cord hydrocele exist: encystic hydrocele and funicular hydrocele. On ultrasonography, encystic hydrocele is a loculated fluid collection within the inguinal canal that does not communicate with the peritoneal cavity (Fig. 3). Funicular hydroceles do communicate with the peritoneal cavity (Fig. 4) [4].

\section{Round Ligament Varices}

The round ligament extends from the lateral uterus to the labia majora and contains arteries, veins, lymphatic vessels, and nerves. Round ligament varices are prominent veins within the round ligament and are more common in pregnancy because of increased venous flow and reduced venous tone [5]. In addition, progesterone receptors are normally present within the round ligament veins, and pregnancy-induced increases in progesterone levels cause dilatation of these veins [5].

Ultrasonography reveals multiple cystic lesions with a "bag of worms" appearance associated with dilated veins (Fig. 5A) [5].

Table 1. Sonography and clinical features of groin abnormalities

\begin{tabular}{lll}
\hline \multicolumn{1}{c}{ Type of lesion } & \multicolumn{1}{c}{ Sonographic feature } & \\
\hline Neoplastic & Clinical feature \\
Lipoma & Hyperechoic & Asymptomatic \\
Epidermoid cyst & Unilocular, heterogeneous, echogenic debris & Occurs usually in women \\
Angiomyofibroblastoma-like tumor & Hyperechoic or hypoechoic & Occurs fifth to eighth decades \\
Liposarcoma & Variable echogenicity & Asymptomatic \\
Synovial sarcoma & Solid or cystic mass & Occurs young adults and adolescents \\
Metastatic mass & Usually hypoechoic & History of primary tumor \\
Nonneoplastic & & \\
Hernia & Variable according to the hernia contents & Groin lump during cough impulse \\
Round ligament varices & "Bag of worms" appearance & Occurs in pregnant women \\
Endometriosis & Solid, cystic, or mixed masses & Cyclic inguinal pain \\
Kimura disease & Homogeneously hypoechoic & Peripheral eosinophilia \\
Castleman disease & Homogeneously hypoechoic, hypervascular & Unicentric or multicentric \\
Hematoma & Variable according to the time & History of trauma \\
Inflammation & Hypoechoic or hyperechoic, poorly defined & Inguinal pain \\
\hline
\end{tabular}




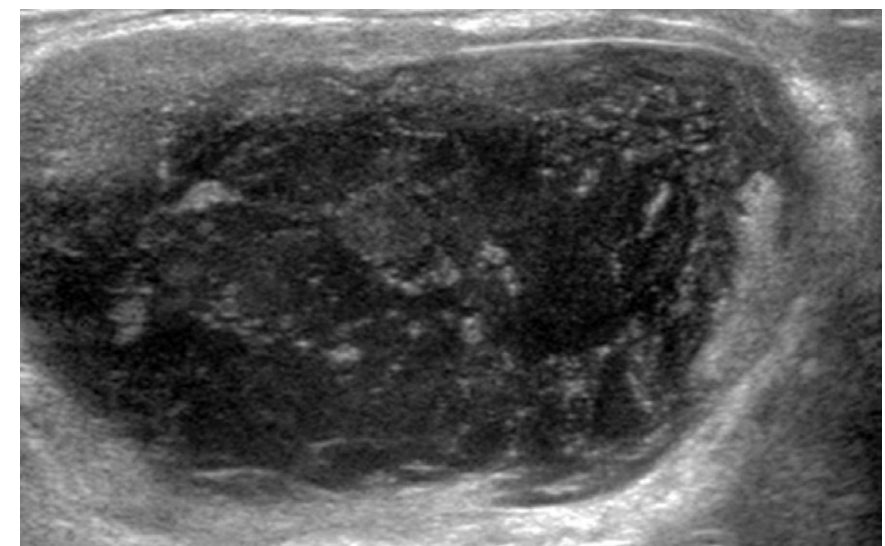

A

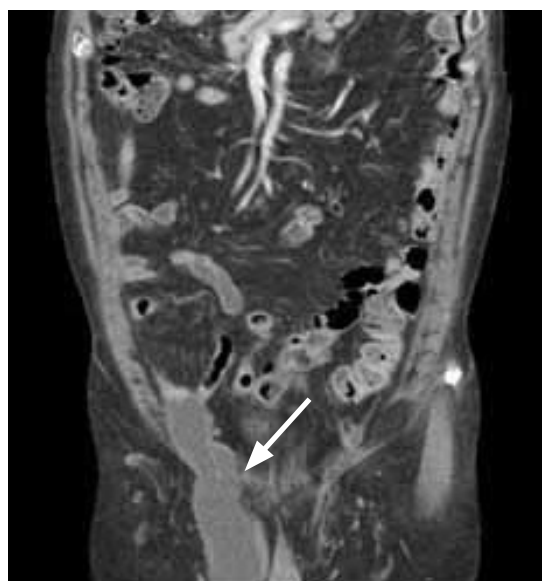

C

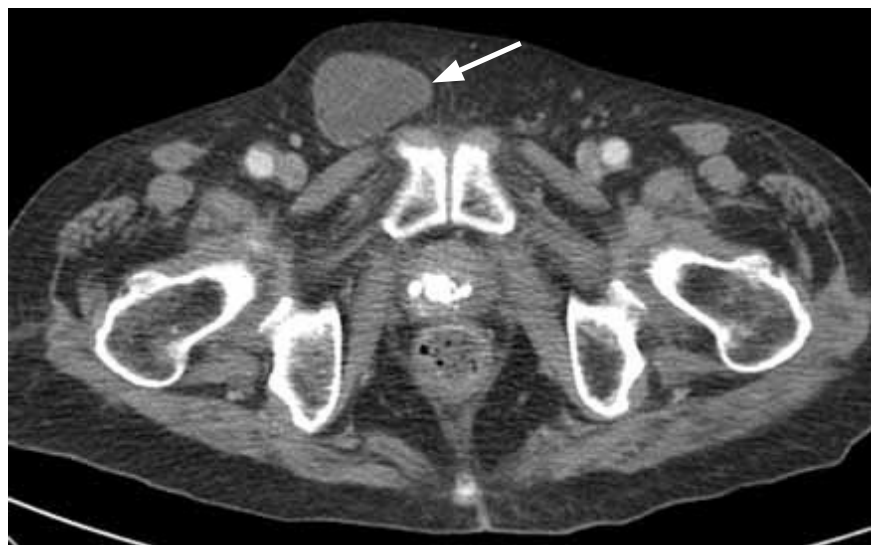

B

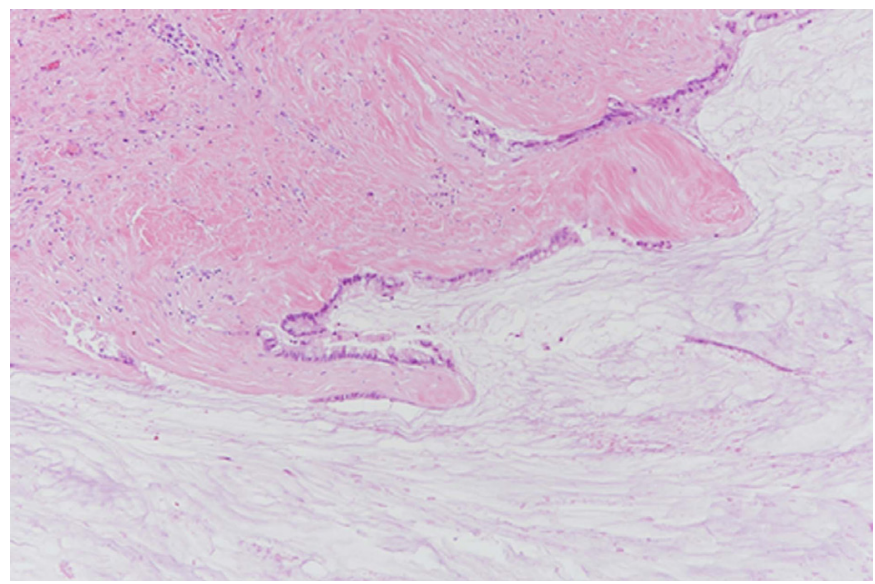

D

Fig. 2. A 91-year-old man with pseudomyxoma peritonei caused by mucinous cystadenocarcinoma of the appendix.

A. Transverse ultrasonography shows a cystic lesion with internal echogenic foci and thickened wall in the right groin. B, C. Transverse and coronal contrast-enhanced computed tomography show a tubular cystic mass in the right groin (arrow). D. Photomicrography shows an abundant mucin pool with a lining of atypical mucinous glandular cells. The atypical mucinous glandular epithelium shows infiltration of stroma $(H \& E, \times 100)$.

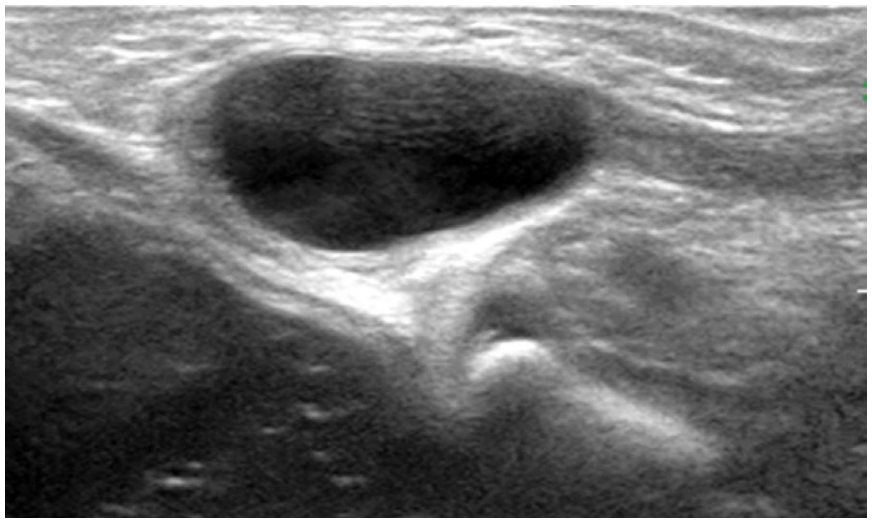

Fig. 3. A 2-year-old boy with an encystic hydrocele. Longitudinal ultrasonography shows an ovoid-shaped, cystic lesion in the left spermatic cord.

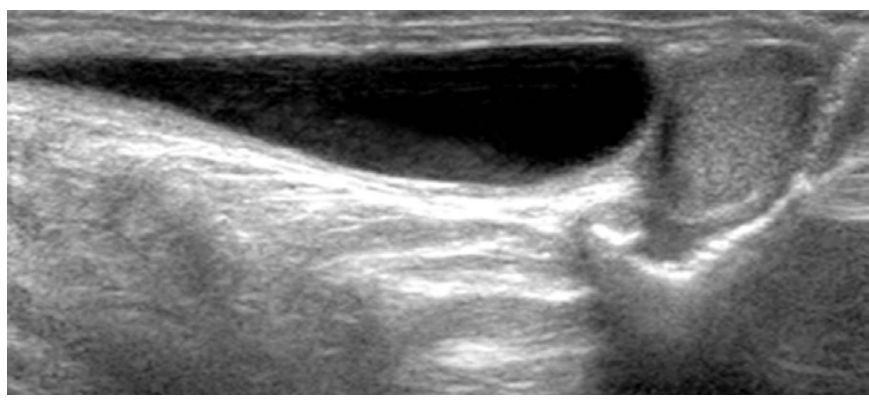

Fig. 4. A 5-year-old boy with a funicular hydrocele. Longitudinal ultrasonography shows a tubular-shaped, cystic lesion in the left spermatic cord. The proximal end of the lesion extends into the peritoneal cavity. 
Color Doppler ultrasonography can confirm the venous flow (Fig. 5B) $[5,6]$. Differentiating these varices from inguinal hernias is important because the management of these two conditions is different [6].

\section{Endometriosis}

Endometriosis is characterized by the proliferation of endometrial tissue at ectopic sites. If the canal of Nuck, a small evagination of the parietal peritoneum that accompanies the round ligament through the inguinal ring into the inguinal canal, is not obliterated, the endometrial tissue may implant in the inguinal area through the canal of Nuck [7]. Most patients have painful swelling of the inguinal region [7].

The ultrasonographic appearance of inguinal endometriosis is variable, including solid masses (Fig. 6), cystic masses (Fig. 7), and combined cystic and solid masses [7].

\section{Kimura Disease}

Kimura disease is an idiopathic chronic inflammatory disorder that usually involves the head and neck area, such as the salivary glands and oral cavity. However, it may also occur in the axilla, groin, trunk, abdomen, and peripheral limbs [8]. The clinical features of Kimura disease are painless subcutaneous soft tissue masses, peripheral

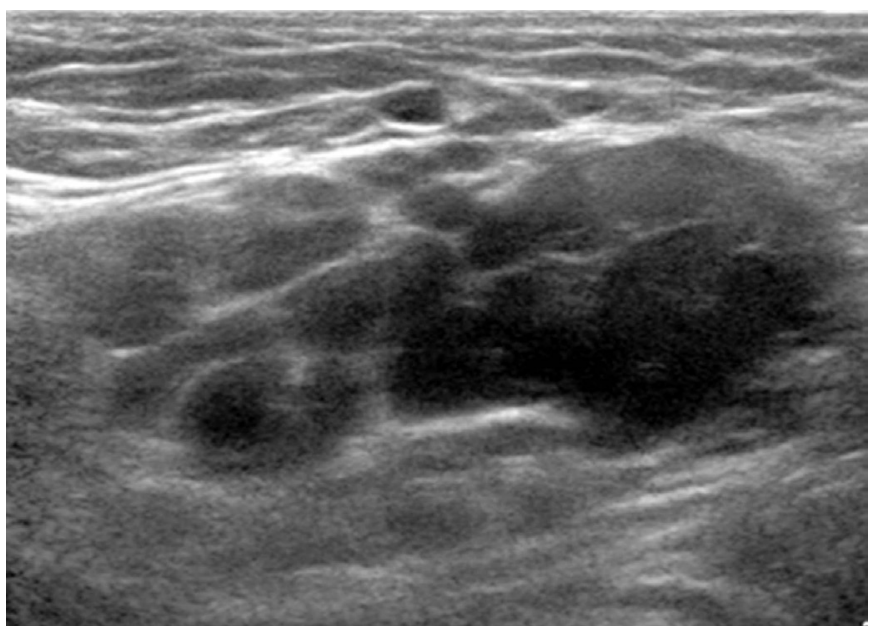

A

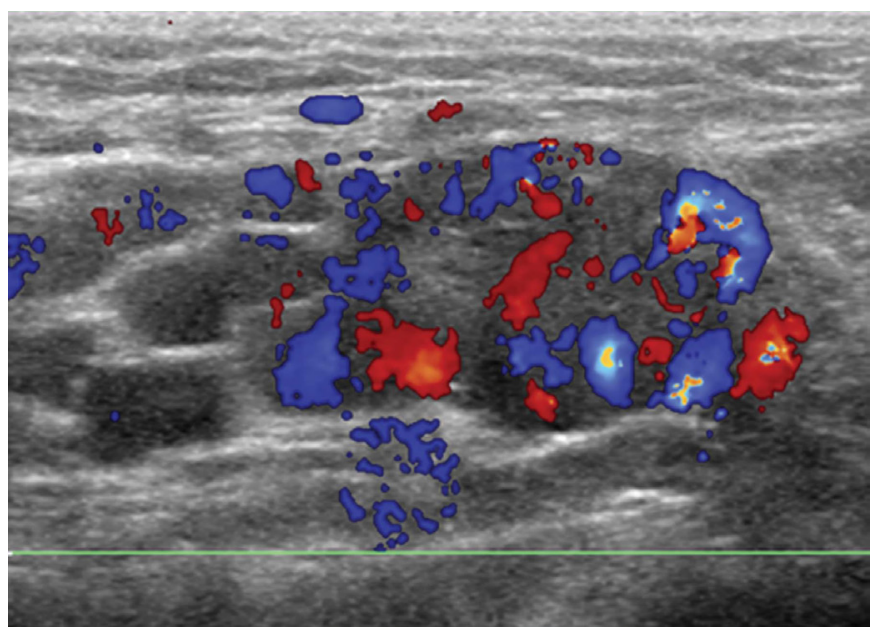

B

Fig. 5. A 29-year-old woman with round ligament varices.

A, B. Longitudinal ultrasonography shows multiple cystic lesions in the left groin. The cystic lesions are filled with blood on color Doppler ultrasonography.

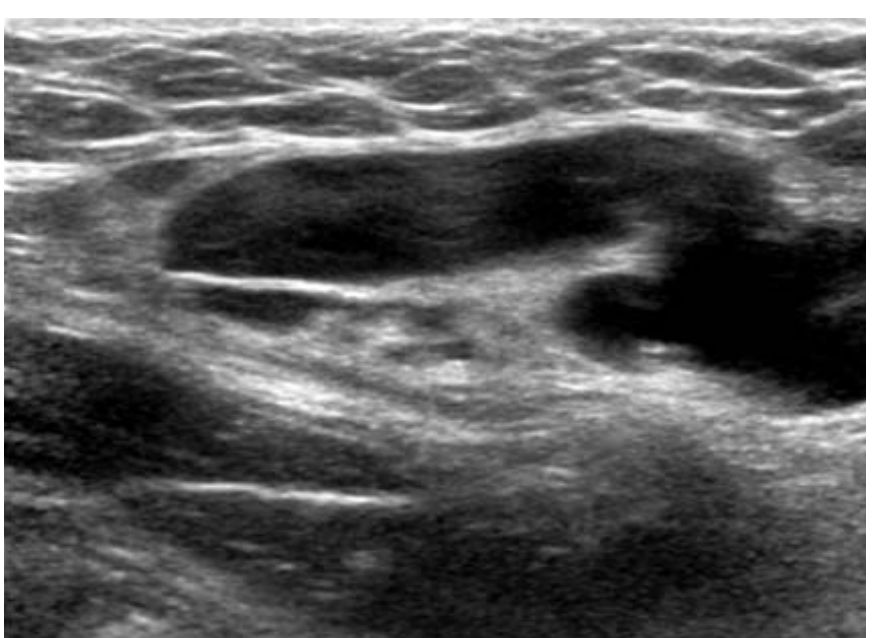

Fig. 6. A 29-year-old woman with endometriosis. Transverse ultrasonography shows a hypoechoic mass with irregular margins in the right groin.

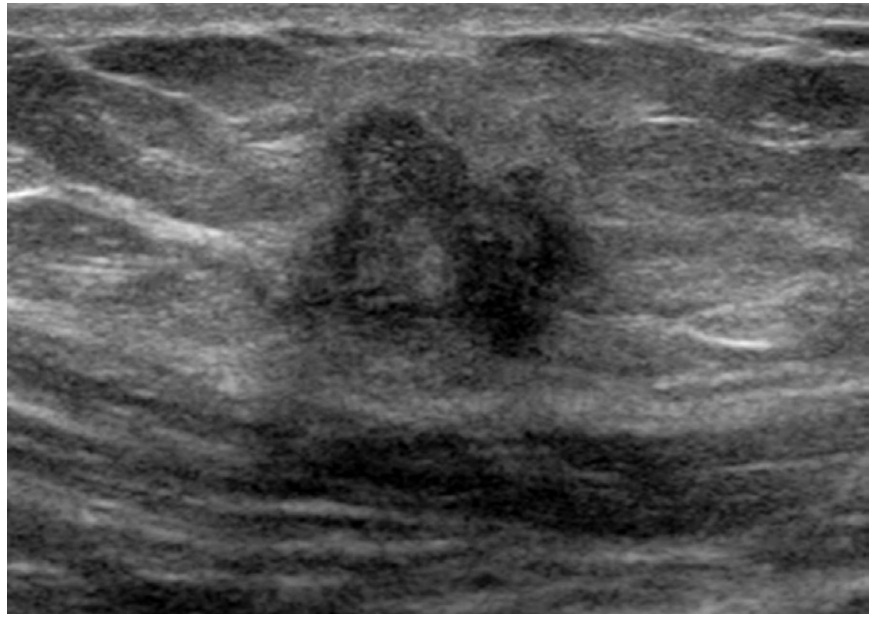

Fig. 7. A 42-year-old woman with endometriosis. Longitudinal ultrasonography shows a multicystic mass in the right groin. 


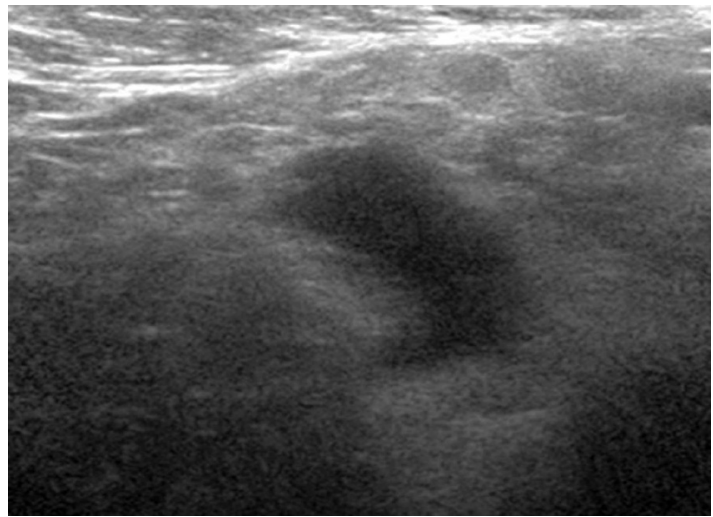

A

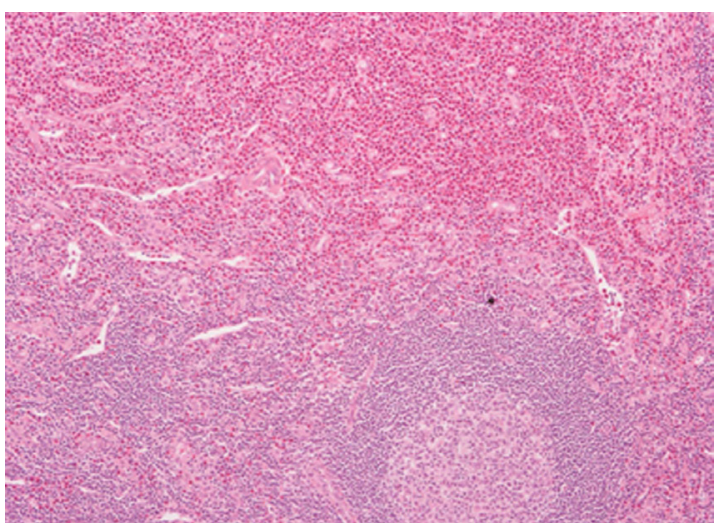

C

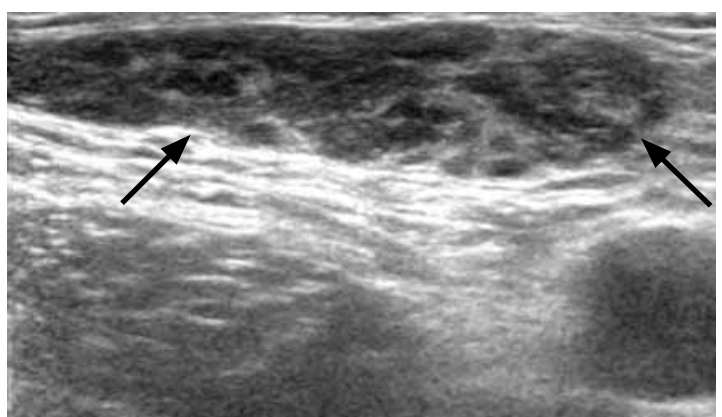

A

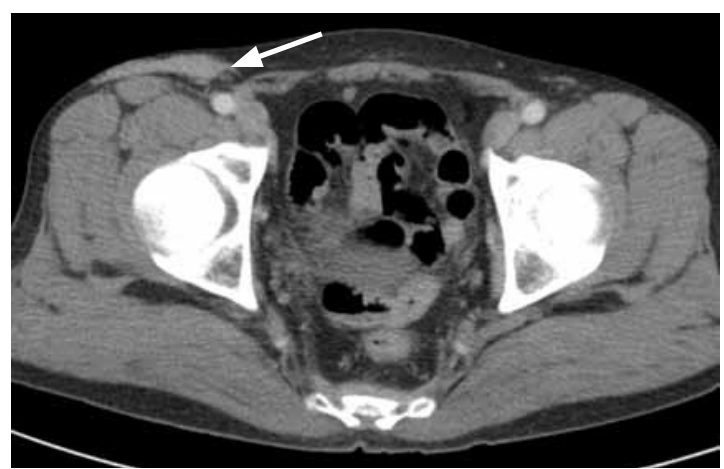

C

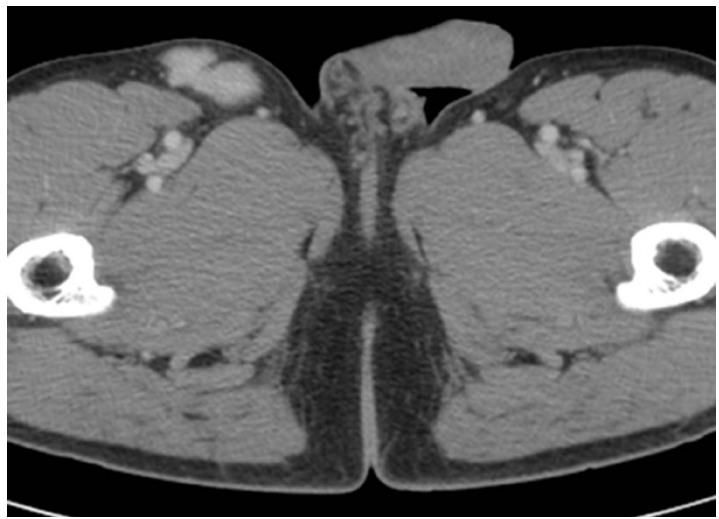

B

Fig. 8. A 49-year-old woman with Kimura disease.

A. Transverse ultrasonography shows a hypoechoic mass with irregular margins in the right groin. B. Contrast-enhanced computed tomography shows a soft tissue mass in the right groin. C. A photomicrograph shows marked infiltration of eosinophils and lymphocytes with a germinal center $(H \& E, \times 100)$.

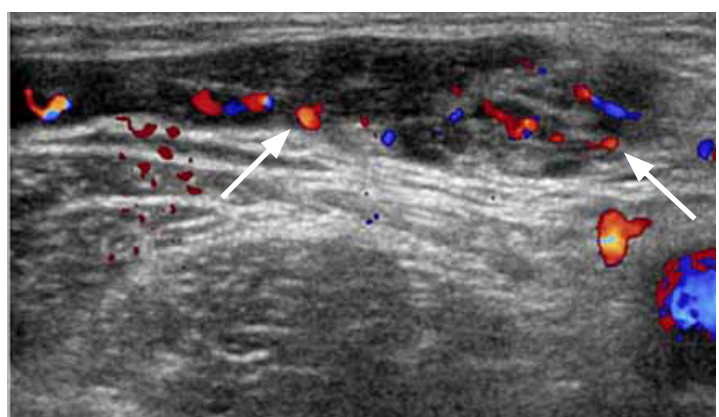

B

Fig. 9. A 55-year-old man with Castleman disease.

A, B. Transverse gray-scale and color Doppler ultrasonography show a heterogeneously hypoechoic mass (arrows) with increased internal blood flow in the right groin. C. Contrast-enhanced computed tomography shows an enhancing soft tissue mass in the right groin (arrow). 
eosinophilia, and elevated serum immunoglobulin E levels [8].

On ultrasonography, it presents as a homogeneously hypoechoic round mass with normal hilar architecture (Fig. 8) [8]. On color Doppler ultrasonography, the disease usually manifests as profuse hilar vascularity with low resistance [9].

\section{Castleman Disease}

Castleman disease is a rare lymphoproliferative disorder and is alternatively known as angiofollicular lymph node hyperplasia or giant lymph node hyperplasia [10]. Castleman disease is classified as unicentric or multicentric based on the extent of lymph node involvement [10]. It can be classified as hyaline vascular, plasma cell, human herpes virus 8-associated, or multicentric Castleman disease

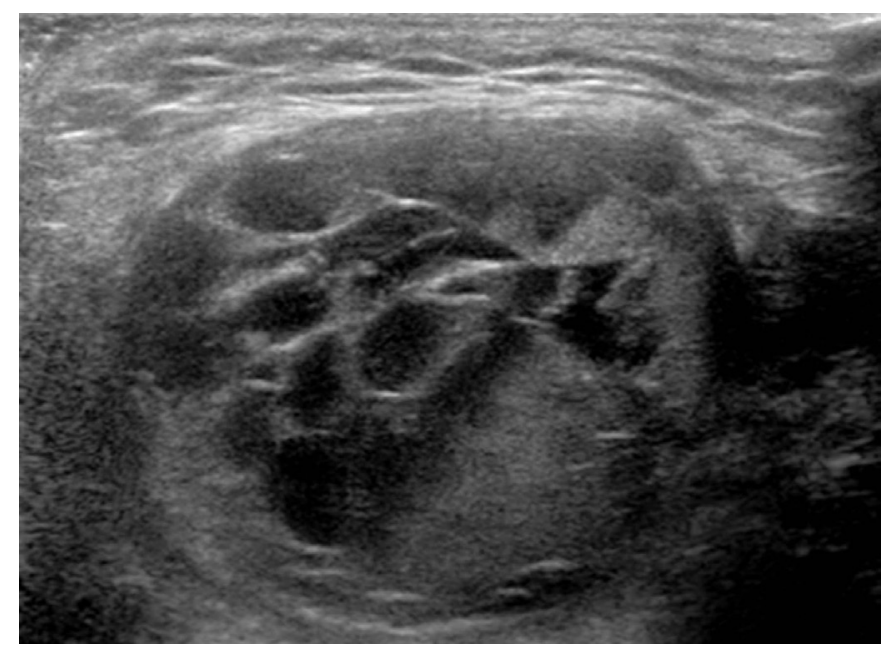

Fig. 10. A 65-year-old man with a hematoma after laparoscopic herniorrhaphy. Transverse ultrasonography shows a mixed anechoic and hyperechoic mass in the right groin.

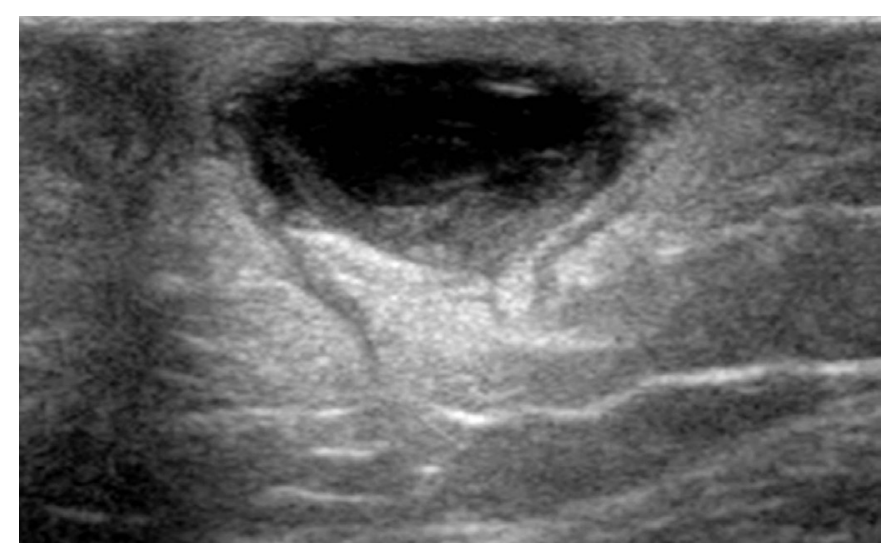

A

Fig. 11. A 35-year-old woman with an abscess.

A, B. Transverse gray-scale and color Doppler ultrasonography show a cystic mass with internal echoes without internal blood flow in the left groin.

e-ultrasonography.org

Ultrasonography 39(2), April 2020

171 not otherwise specified [10], and occurs in the chest (70\%), neck (15\%), or abdomen and pelvic regions (15\%) [10].

Castleman disease is usually seen as a well-defined, homogeneously hypoechoic mass on ultrasonography (Fig. 9A) [11]. Color Doppler ultrasonography reveals a hypervascular mass (Fig. 9B) [11].

\section{Hematoma and Inflammation}

The echogenicity of hematoma varies according to stage. Initially, the hematoma is hyperechoic, but then becomes gradually hypoechoic and anechoic (Fig. 10) [2].

Inflammation and abscesses may occur in the groin. Ultrasonography shows variable echogenicity, which ranges from anechoic to hypoechoic (Fig. 11). The differentiation of tumors, hematomas, and inflammation may be difficult on ultrasonography.

\section{Neoplastic Lesions}

\section{Benign Tumors}

Lipoma is the most common benign tumor of the groin. On ultrasonography, it can have variable echogenicity compared with the surrounding soft tissues, ranging from hyperechoic to hypoechoic (Fig. 12). It may be difficult or impossible to differentiate from liposarcoma $[1,2]$.

Epidermoid cyst is a rare congenital lesion of ectodermal origin that usually affects middle-aged women and can occur anywhere from the head to toe. It is known to have a component of stratified squamous epithelium with a mixture of desquamated debris, cholesterol, keratin, and water. Ultrasonography shows a heterogeneously cystic mass containing echogenic debris (Fig. 13) [12]. The echogenicity varies according to the composition of the lesion [13].

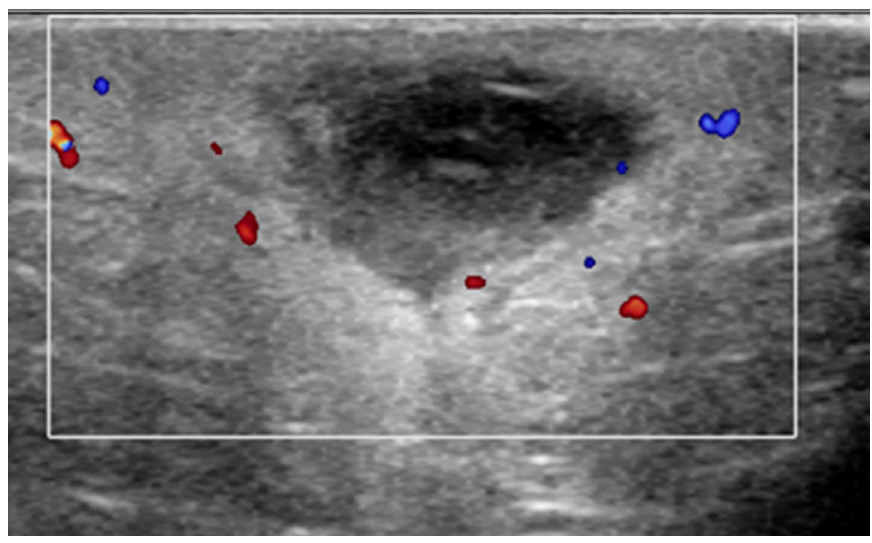

B 


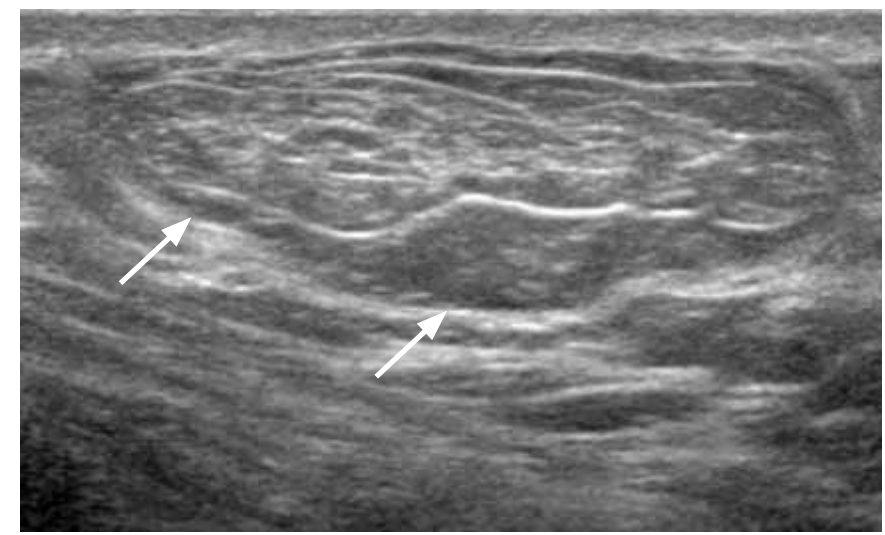

Fig. 12. A 61-year-old man with lipoma. Longitudinal ultrasonography shows a mixed hyperechoic and hypoechoic mass in the left groin (arrows).

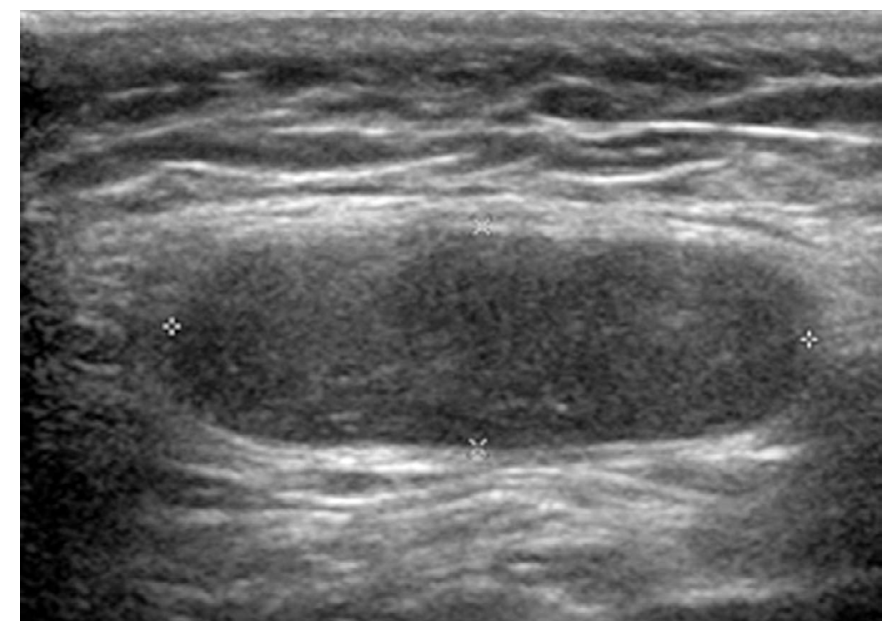

A

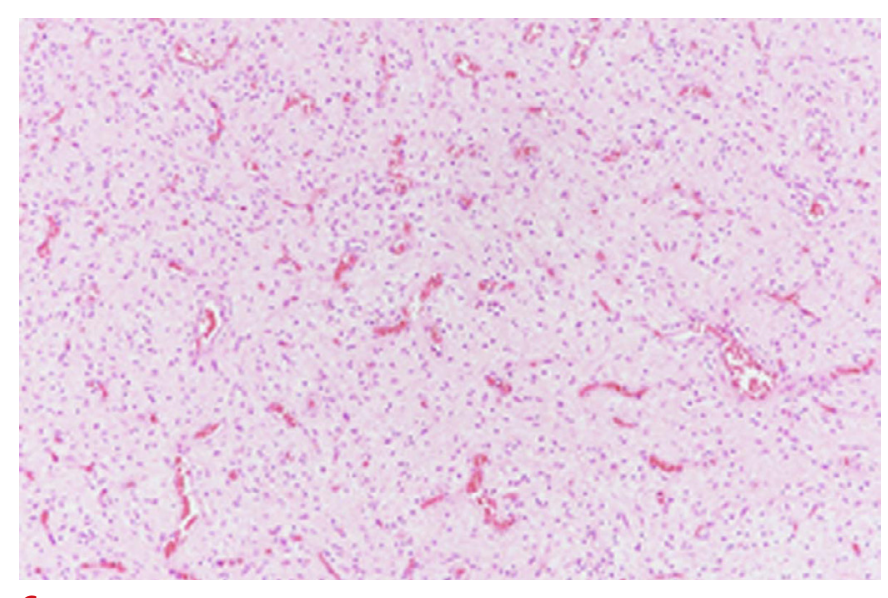

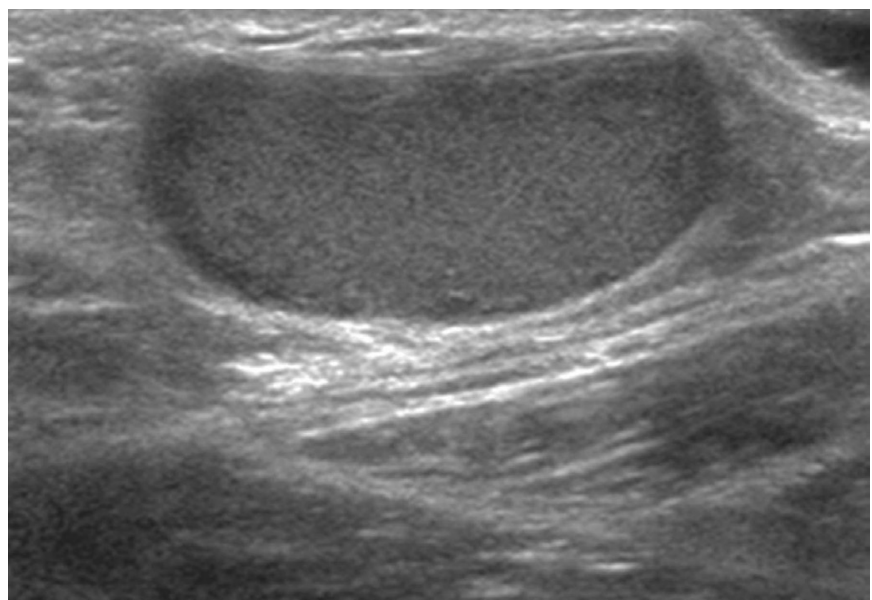

Fig. 13. A 42-year-old man with an epidermoid cyst. Longitudinal ultrasonography shows an ovoid-shaped, hypoechoic mass with internal echoes and posterior enhancement in the right groin.

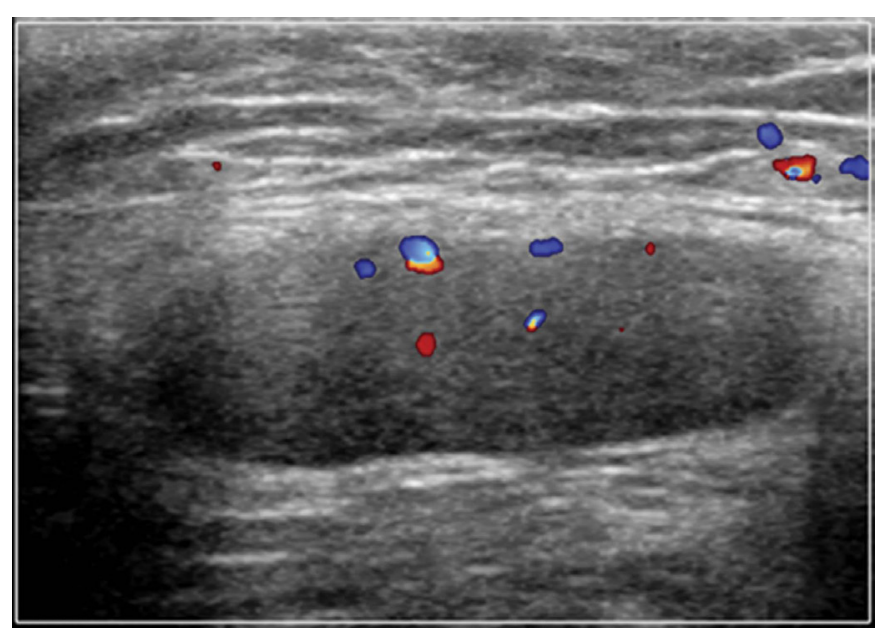

B

Fig. 14. A 43-year-old man with an angiomyofibroblastoma-like tumor.

A, B. Longitudinal gray-scale and color Doppler ultrasonography show an ovoid-shaped hypoechoic lesion with internal blood flow in the left inguinal region. C. A microphotograph shows bland spindle cells with scant, lightly eosinophilic cytoplasm with ill-defined borders. Additionally, prominent small to medium-sized vessels with fibrous stroma are seen $(H \& E, \times 100)$. 
Angiomyofibroblastoma-like tumor or cellular angiofibroma is a rare mesenchymal tumor that occurs in the inguinal area, perineum, scrotum, and vulva [14]. It has been suggested that its histogenesis arises from perivascular stem cells with a capacity for fatty and myofibroblastic differentiation [14]. This disease commonly occurs during the fifth to eighth decades of life [14]. On ultrasonography, the mass usually presents as a well-defined mass in the subcutaneous layer of the inguinal region that is heterogeneous and isoechoic to the surrounding subcutaneous fat [15]. It is usually hypervascular on color Doppler ultrasonography [15]. In a case that we experienced, the mass appeared hypoechoic and hypervascular (Fig. 14). Other benign tumors of the groin include leiomyoma, neurofibroma, desmoid tumor, dermoid cyst, and lymphangioma.

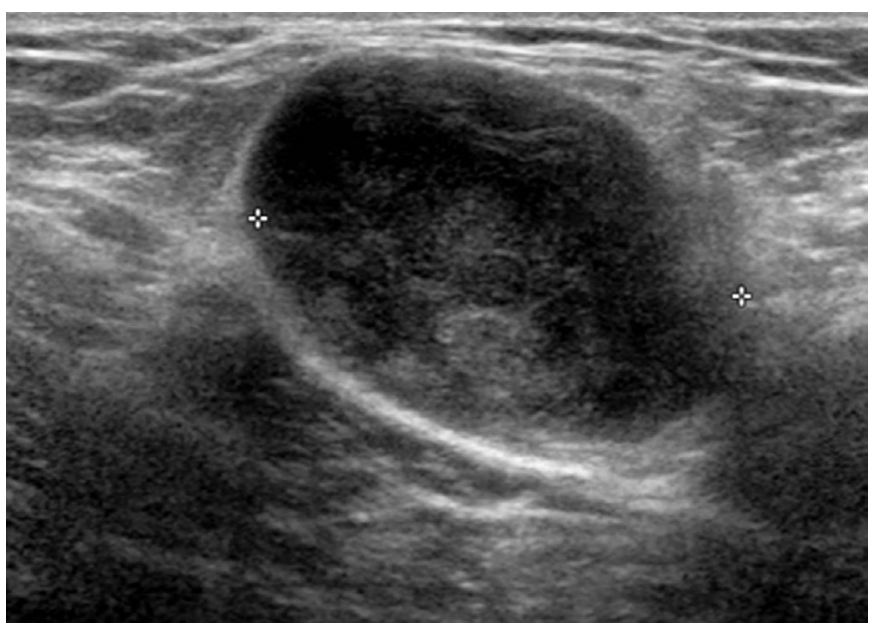

A

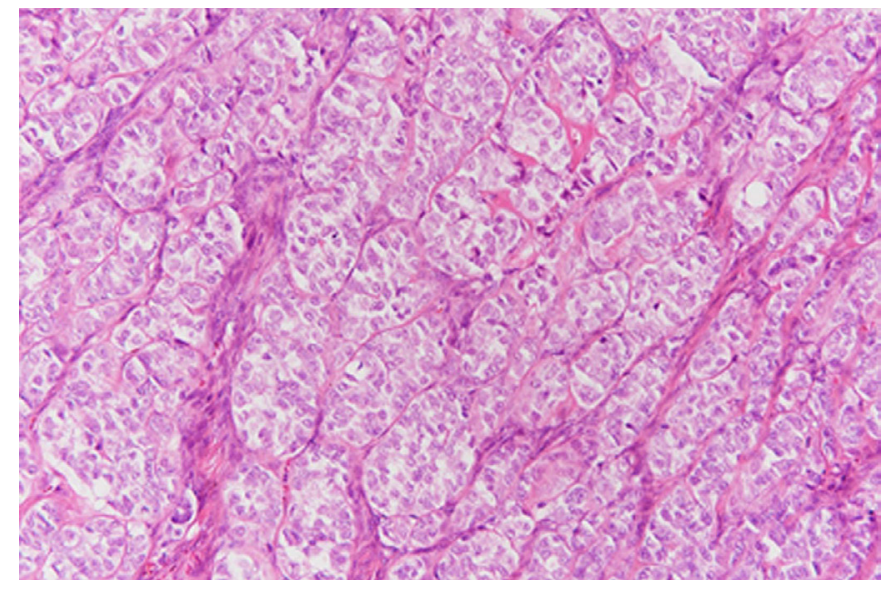

C

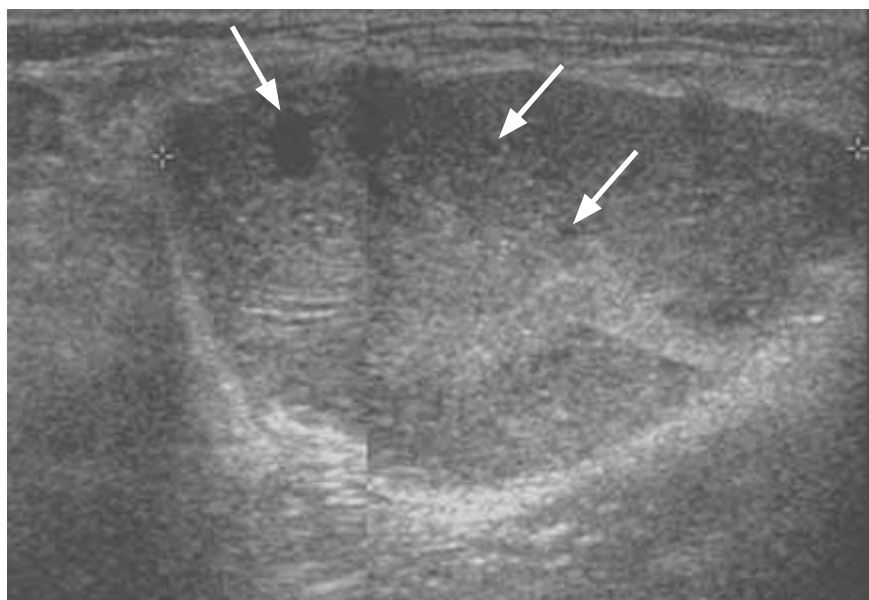

Fig. 15. A 45-year-old man with myxoid liposarcoma. Longitudinal ultrasonography shows a well-defined hypoechoic mass with tiny cystic foci (arrows) in the left groin.

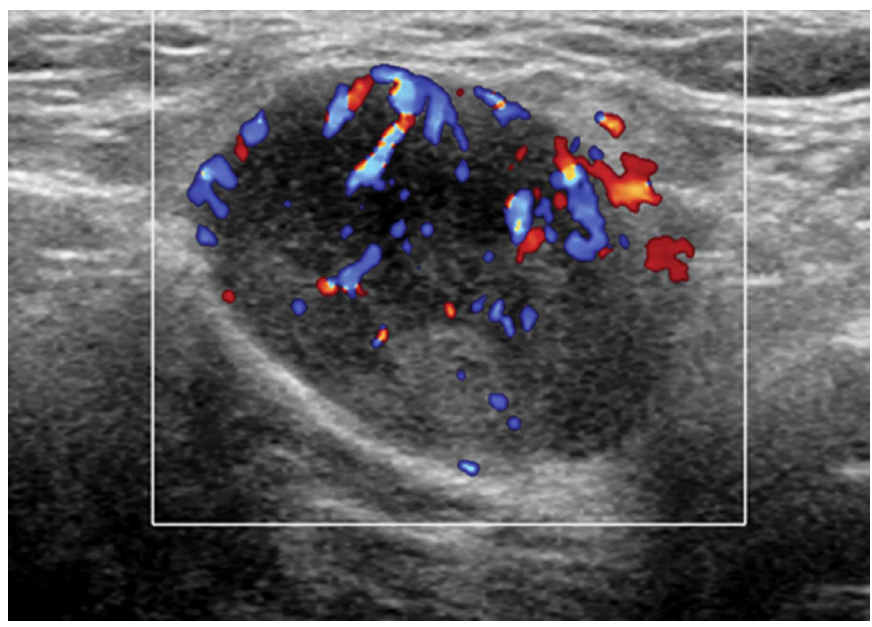

B

Fig. 16. A 45-year-old woman with synovial sarcoma.

A, B. Transverse gray-scale and color Doppler ultrasonography show a well-defined, hypoechoic mass with increased internal blood flow in the left groin. C. A microphotograph shows atypical spindle cell nests surrounded by a thin fibrous capsule. The tumor cells have pleomorphism and prominent nucleoli $(H \& E, \times 200)$. 


\section{Malignant Tumors}

Most malignant tumors in the groin are sarcomas and the most common sarcomas are rhabdomyosarcoma and liposarcoma [16]. The former frequently occurs in children and the latter is more common in adults [16].

Liposarcoma is a bulky yellow tumor similar to lipoma but is generally more complex and contains areas of prominent sclerosis [16]. Liposarcoma can be classified as well differentiated, dedifferentiated, myxoid, pleomorphic, or not otherwise specified. The ultrasonographic findings of liposarcoma are variable and nonspecific (Fig. 15) [16].

Synovial sarcoma is a mesenchymal tumor of uncertain pathogenesis that accounts for $10 \%$ of all primary soft tissue malignant tumors. Although the tumor often occurs close to joints, tendons, and bursae, it can appear in a variety of locations, including the head and neck, retroperitoneum, mediastinum, and groin [17].

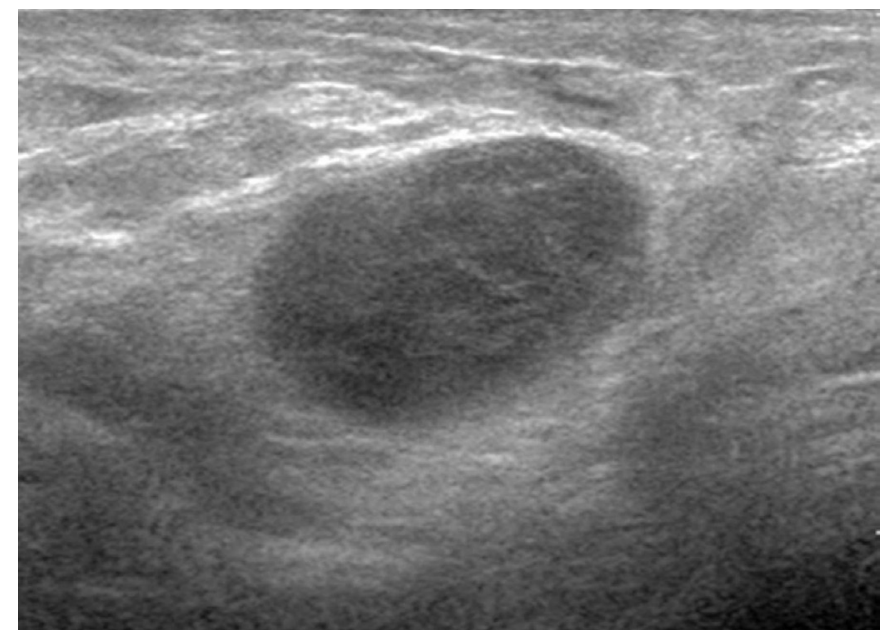

A

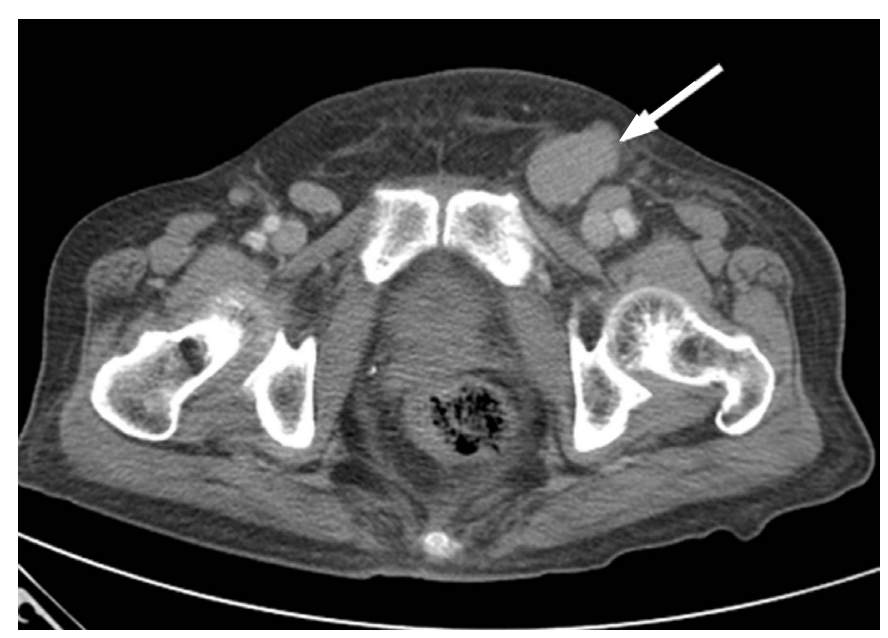

Synovial sarcoma can occur at all ages but is most commonly seen in young adults and adolescents. It usually appears as a solid mass (Fig. 16) [2], although it may also appear as a cystic mass [18].

Other primary malignant tumors involving the groin include malignant fibrous histiocytoma, fibrosarcoma, and lymphoma (Fig. 17) [19].

Secondary metastatic disease from melanoma, neuroendocrine carcinoma (Fig. 18), and carcinomas of the lung, breast, urinary bladder (Fig. 19), ovary, vulva, and colon can occur in the groin $[1,2]$. The ultrasonographic findings of these masses are usually hypoechoic [2]. Although lymphoma is markedly hypoechoic [20], the differential diagnosis of these masses is difficult. Metastatic masses should be distinguished from benign lymph nodes. On ultrasonography, a normal lymph node usually appears as an oval mass with a hypoechoic peripheral zone and echogenic center [20]. Metastatic lymph nodes usually have a round shape, normal

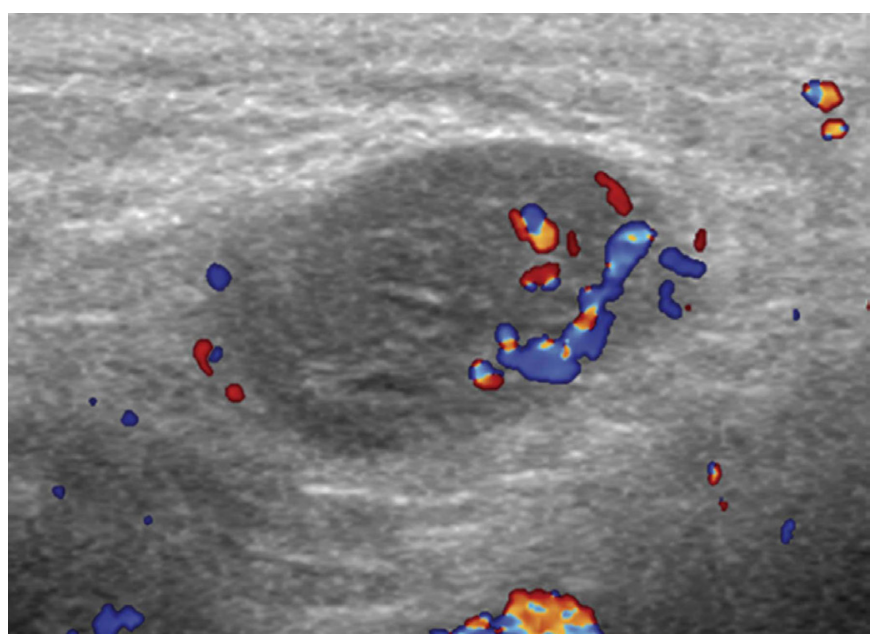

B

Fig. 17. A 76-year-old woman with non-Hodgkin lymphoma.

A, B. Transverse gray-scale and color Doppler ultrasonography show a hypoechoic mass with increased blood flow within the mass in the left groin. C. Contrast-enhanced computed tomography shows a soft tissue mass in the left groin (arrow). 


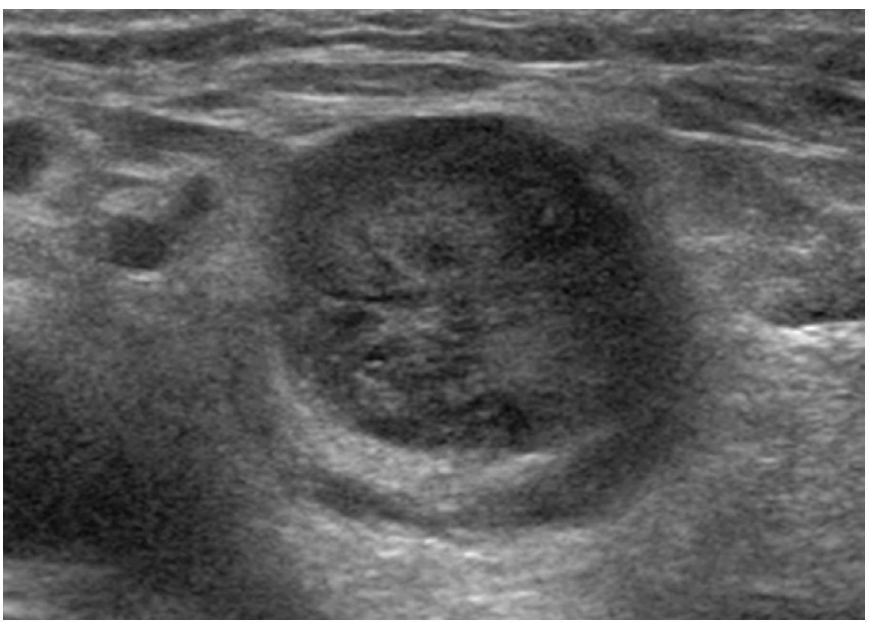

A

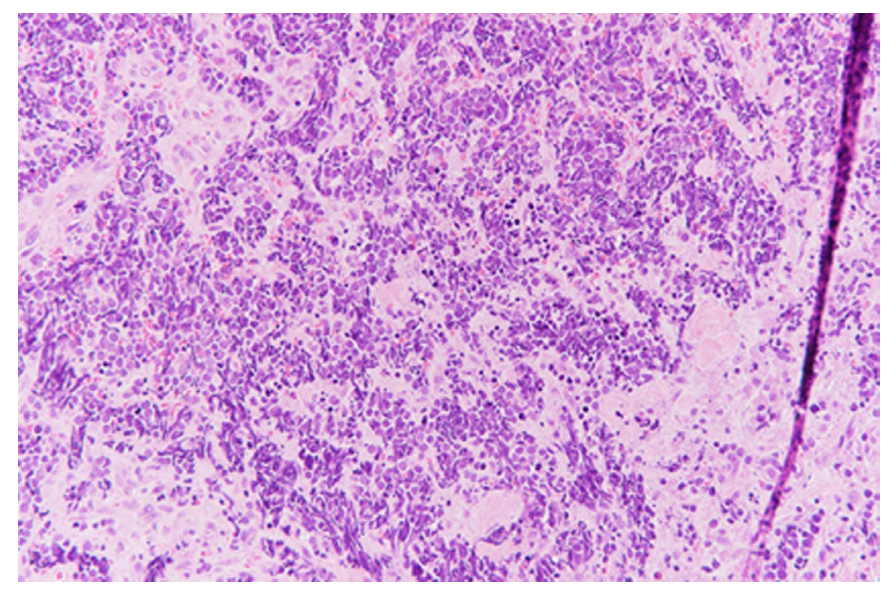

C

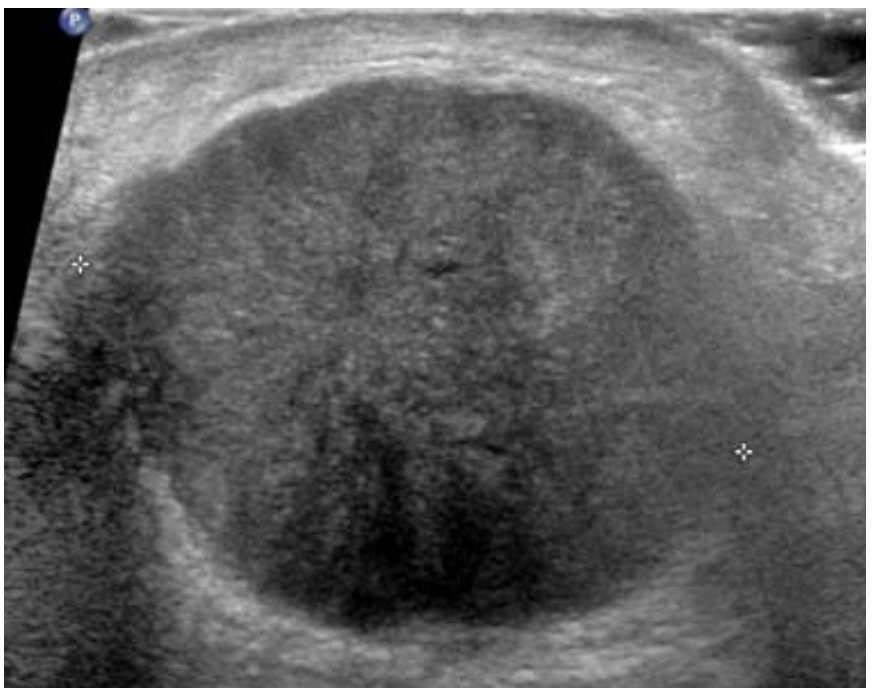

A

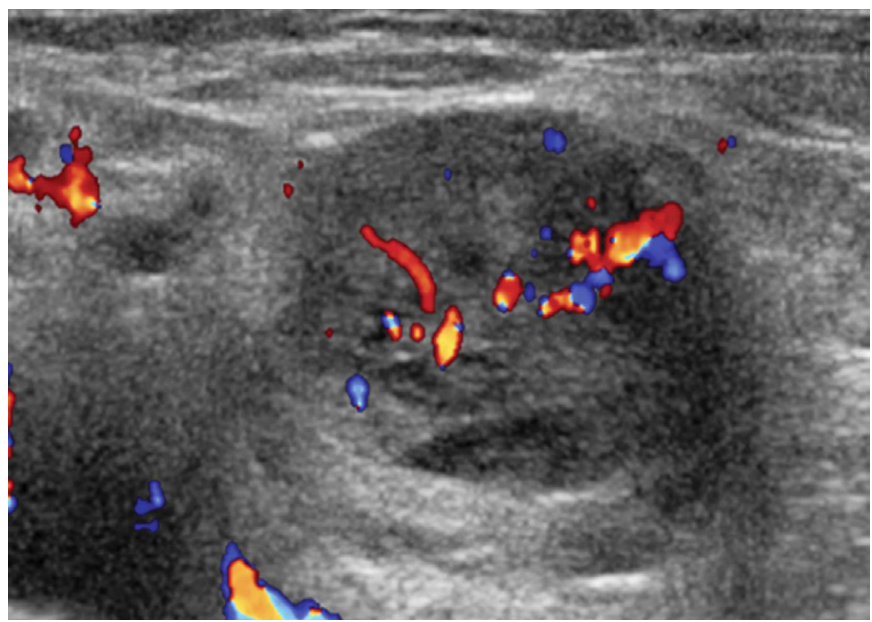

B

Fig. 18. A 68-year-old man with metastatic neuroendocrine carcinoma.

A, B. Transverse gray-scale and color Doppler ultrasonography show a well-defined, round, heterogeneously hypoechoic mass with increased internal blood flow in the right groin. C. A microphotograph shows atypical cell nests with uniform tumor cells. The tumor cells have many mitotic figures and prominent nucleoli $(H \& E, \times 200)$.

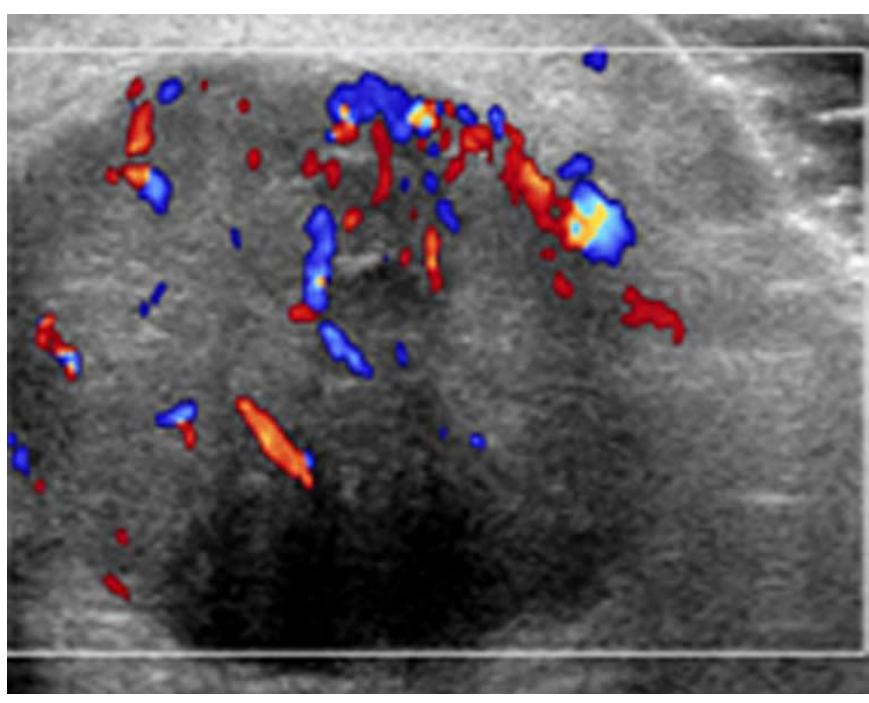

B

Fig. 19. A 91-year-old man with metastasis from bladder cancer.

A, B. Transverse gray-scale and color Doppler ultrasonography show a well-defined, round, hypoechoic mass with increased internal blood flow in the left groin. 


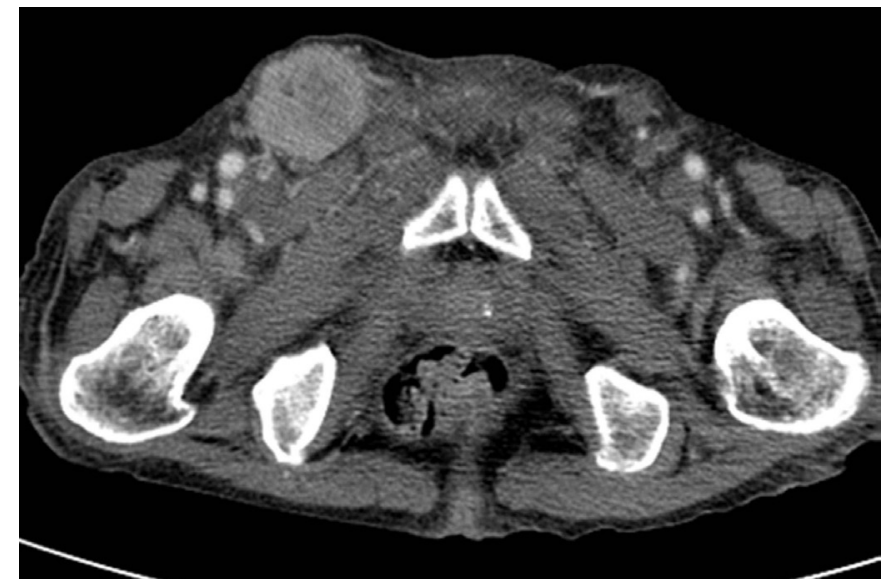

C

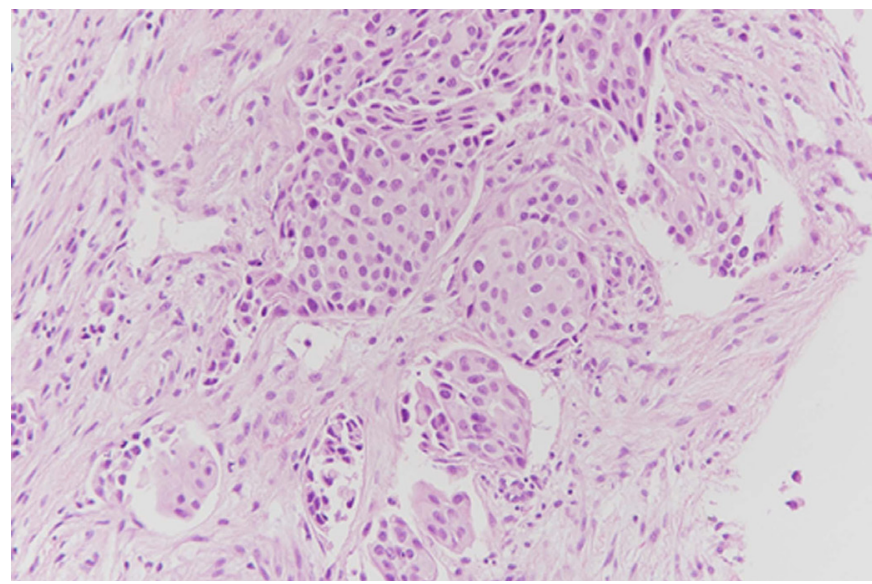

D

Fig. 19. C. Contrast-enhanced computed tomography shows a soft tissue mass in the right groin. D. A microphotograph shows atypical cell nests with desmoplastic stroma (H\&E, ×200).

or absent hilus, and eccentric widening of the cortex on gray-scale ultrasonography, and a high resistive index and pulsatility index on color Doppler ultrasonography [20].

\section{Conclusion}

In patients with groin lesions, ultrasonography is considered to be the first-line imaging modality and may provide important information about the anatomical location, size, and whether the lesion is solid or cystic. However, there is substantial overlap in the ultrasonographic findings of various groin lesions. Although ultrasonography is nonspecific for distinguishing between many kinds of groin lesions, familiarity with the ultrasonographic findings of groin lesions facilitates accurate diagnosis and treatment.

ORCID: Dal Mo Yang: https://orcid.org/0000-0001-7766-5826; Hyun Cheol Kim: https://orcid.org/0000-0002-3121-092X; Sang Won Kim: https://orcid.org/00000002-1999-9163; Kyu Yeoun Won: https://orcid.org/0000-0002-9520-9952

\section{Author Contributions}

Conceptualization: Yang DM. Data acquisition: Yang DM, Kim HC, Kim SW. Data analysis or interpretation: Yang DM, Kim HC, Kim SW, Won KY. Drafting of the manuscript: Yang DM, Won KY. Critical revision of the manuscript: Yang DM, Kim HC, Kim SW, Won KY. Approval of the final version of the manuscript: all authors.

\section{Conflict of Interest}

No potential conflict of interest relevant to this article was reported.

\section{References}

1. Shadbolt $C L$, Heinze $S B$, Dietrich RB. Imaging of groin masses: inguinal anatomy and pathologic conditions revisited. Radiographics 2001;21 Spec No:S261-S271.

2. Yang DM, Kim HC, Lim JW, Jin W, Ryu CW, Kim GY, et al. Sonographic findings of groin masses. J Ultrasound Med 2007;26:605-614.

3. Que Y, Tao C, Wang X, Zhang Y, Chen B. Pseudomyxoma peritonei: some different sonographic findings. Abdom Imaging 2012;37:843848.

4. Martin LC, Share JC, Peters C, Atala A. Hydrocele of the spermatic cord: embryology and ultrasonographic appearance. Pediatr Radiol 1996;26:528-530.

5. Uzun $M$, Akkan K, Coskun B. Round ligament varicosities mimicking inguinal hernias in pregnancy: importance of color Doppler sonography. Diagn Interv Radiol 2010;16:150-152.

6. Ryu $\mathrm{KH}$, Yoon JH. Ultrasonographic diagnosis of round ligament varicosities mimicking inguinal hernia: report of two cases with literature review. Ultrasonography 2014;33:216-221.

7. Yang DM, Kim HC, Ryu JK, Lim JW, Kim GY. Sonographic findings of inguinal endometriosis. J Ultrasound Med 2010;29:105-110.

8. Ahuja AT, Loke TK, Mok CO, Chow LT, Metreweli C. Ultrasound of Kimura's disease. Clin Radiol 1995;50:170-173.

9. Ahuja A, Ying M, Mok JS, Anil CM. Gray scale and power Doppler sonography in cases of Kimura disease. AJNR Am J Neuroradiol 2001;22:513-517.

10. Bonekamp D, Horton KM, Hruban RH, Fishman EK. Castleman disease: the great mimic. Radiographics 2011;31:1793-1807.

11. Konno K, Ishida H, Hamashima Y, Komatsuda T, Masamune O. Color Doppler findings in Castleman's disease of the mesentery. J Clin Ultrasound 1998;26:474-478. 
12. Sherer DM, Zinn $H$, Gavrilescu $T$, Abdelmalek $E$, Hellmann $M$, Sokolovski $M$, et al. Transvaginal sonographic diagnosis of a large retroperitoneal pelvic epidermoid cyst (monodermal teratoma). J Ultrasound Med 2006;25:265-268.

13. Ahn SE, Park SJ, Moon SK, Lee DH, Lim JW. Sonography of abdominal wall masses and masslike lesions: correlation with computed tomography and magnetic resonance imaging. J Ultrasound Med 2016;35:189-208.

14. Nucci MR, Granter SR, Fletcher CD. Cellular angiofibroma: a benign neoplasm distinct from angiomyofibroblastoma and spindle cell lipoma. Am J Surg Pathol 1997;21:636-644.

15. Miyajima K, Hasegawa S, Oda Y, Toyoshima S, Tsuneyoshi M, Motooka M, et al. Angiomyofibroblastoma-like tumor (cellular angiofibroma) in the male inguinal region. Radiat Med 2007;25:173-177.
16. Lipset RE, Kirpekar M, Cooke KS, Abiri MM. US case of the day. Myxoid liposarcoma of the spermatic cord. Radiographics 1997; 17:1316-1318.

17. Jones $B C$, Sundaram M, Kransdorf MJ. Synovial sarcoma: MR imaging findings in 34 patients. AJR Am J Roentgenol 1993; 161:827-830.

18. Park JK, Ham SY, Hwang JC, Jeong YK, Lee JH, Yang SO, et al. Synovial sarcoma of the head and neck: a case of predominantly cystic mass. AJNR Am J Neuroradiol 2004;25:1103-1105.

19. Bertolotto $M$, Borsato $A$, Derchi LE. Lymphoma of the spermatic cord: sonographic appearance. J Clin Ultrasound 2014;42:509-512.

20. Vassallo P, Wernecke K, Roos N, Peters PE. Differentiation of benign from malignant superficial lymphadenopathy: the role of highresolution US. Radiology 1992;183:215-220. 